1. Semyon Gluzman, Psychiatrist, whose continued imprisonment in defiance of international protest it again deplores;

2. Alexander Podrabinex, Medical Assistant, whose research into the abuse of psychiatry and whose book Punitive Medicine has led to judicial persecution and now to a sentence of exile;

3. Alexander Voloshanovich, Psychiatrist, whose clinical reports have been invaluable for the brave work in Moscow of the Working Commission to Investigate the Use of Psychiatry for Political Purposes:

4. Vladimir Moskalkov, Psychiatrist, whose testimony in support of Alexander Podrabinek at his trial supplied a most worthy example of ethical medical behaviour.'

\title{
ASSESSORS' REPORTS ON ADVISORY APPOINTMENTS COMMITTEES
}

Since 1970, College assessors on consultant appointments committees have been asked to supply information on a confidential basis about applicants and those interviewed. The information includes the number of applicants, assessors' opinions on their training and experience, numbers interviewed, their quality, and the main deficiencies of all those seen; finally, the number of overseas graduates applying or short-listed. In addition, the assessors are asked to make any general comments about the interview, and these have sometimes taken the form of a letter or memorandum, paricularly when the assessor has felt unhappy about the candidate appointed.

An analysis has been made of 395 returns (from 56 per cent response rate) from England and Wales for the years $1974-7$ covering all specialties.

\section{Results}

These are presented in summary form in Tables 1, 2 and 3. The proportion of posts where no one was appointed was wide-ranging, from 8 per cent for psychotherapy to 42 per cent for subnormality. What is of interest is that six jobs in psychogeriatrics were unfilled because of deficiencies in the post rather than in the candidates. Deficiencies in the posts were also mentioned twice for subnormality and once for general psychiatry.

The most frequently mentioned deficiencies in the candidates were in experience and training, including experience in general psychiatry in those applying for specialist posts; less frequently personality and language problems were mentioned. In detail, inadequate experience was mentioned $77,36,39,13$, 10,5 and 8 times in general, child, subnormality, psychogeriatrics, forensic and the dependencies respectively. The corresponding figures for personality problems showed a much wider range, being $34,4,10$, $3,3,3$ and 0 . Deficiencies in comprehension and the use of English were commented on in the returns of 9 general psychiatry, 8 subnormality and 3 child psychiatry interviews.

No detailed analysis was made of which areas and what types of post were least and most successful in attracting good candidates, but the impression, which will come as no surprise, is that teaching hospitals on the whole fared better than non-teaching ones and that posts in the South and South-West even for nonteaching hospitals attracted a larger share of wellqualified candidates than posts in the Midlands and the North.

What changes have there been over time? Because of the small numbers a detailed analysis was made for general psychiatry only. There has perhaps been a slight rise in the number of very good and good interviewees, with a correspondingly slight fall in the indifferent and poor ones, but the results as shown in Table 2 are not entirely consistent. The mean number of applicants per post for general psychiatry has shown a consistent fall over the four years analysed.

Impressionistically, there has been a definite improvement in the calibre of those applying in the specialties of forensic psychiatry, psychotherapy and the addictions, while the proportion of unfilled posts in psychogeriatrics has dropped over the years. For example, in 1974 four posts only were filled out of seven.

\section{Conclusions}

The returns make far from happy reading. Too many of the senior registrars applying have had quite inadequate experience, at least in the view of the College assessor, and there are frequent comments on 
TABLE I

Advisory Appointments Committees Analysis 1974-7

\begin{tabular}{|c|c|c|c|c|c|c|}
\hline Specialty & $\begin{array}{l}\text { No. of } \\
\text { Posts }\end{array}$ & $\begin{array}{l}\text { No. }(+\%) \text { where } \\
\text { no appointment } \\
\text { made }\end{array}$ & $\begin{array}{l}\text { No. }(+\%) \text { where } \\
\text { reservations } \\
\text { expressed about } \\
\text { successful } \\
\text { candidate }\end{array}$ & $\begin{array}{l}\text { No. }(+\%) \text { Home } \\
\text { Graduates }\end{array}$ & $\begin{array}{l}\text { No. (+\%) Over- } \\
\text { seas Graduates }\end{array}$ & $\begin{array}{c}\text { \% of SRs born } \\
\text { Overseas } \\
1974-8^{*}\end{array}$ \\
\hline General Psychiatry & 173 & $40(23)$ & $15(11)$ & $96(72)$ & $37(28) \dagger$ & 36 \\
\hline Child Psychiatry & 84 & $11(13)$ & $20(27)$ & $55(75)$ & $18(25)$ & 34 \\
\hline Subnormality & 57 & $24(42)$ & $6(18)$ & $18(55)$ & $15(45)$ & 73 \\
\hline Psychogeriatrics & 31 & $10(32)$ & $8(38)$ & $12(57)$ & $9(43)$ & 一 \\
\hline Psychotherapy & 26 & $2(8)$ & $3(13)$ & $18(75)$ & $6(25)$ & - \\
\hline Forensic Psychiatry & 13 & $2(15)$ & 0 & $10(90)$ & $1(9)$ & - \\
\hline Alcoholism \& Addiction & 11 & $4(36)$ & $2(27)$ & $7(100)$ & 0 & - \\
\hline
\end{tabular}

*Source DHSS Research and Statistics Division National Manpower Statistical Tables 1974-8

$\dagger 1974=8$ (36\%), $1975=14$ (35\%), 1976=7 (33\%), $1977=8$ (20\%)

TABLE II

Quality of Candidates interviewed (Percentages rounded)

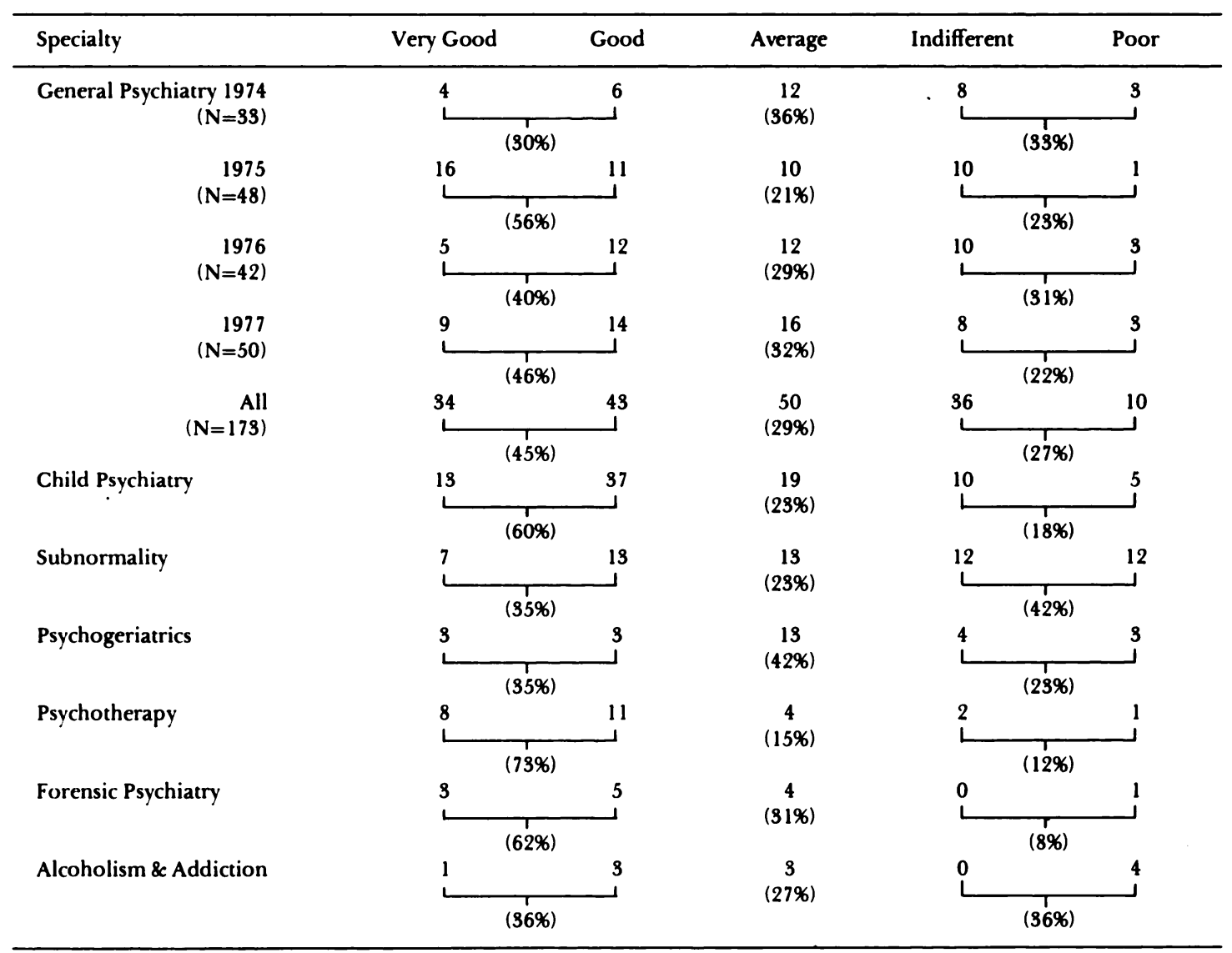


TABLE III

Advisory Appointments Committees Analysis 1974-7

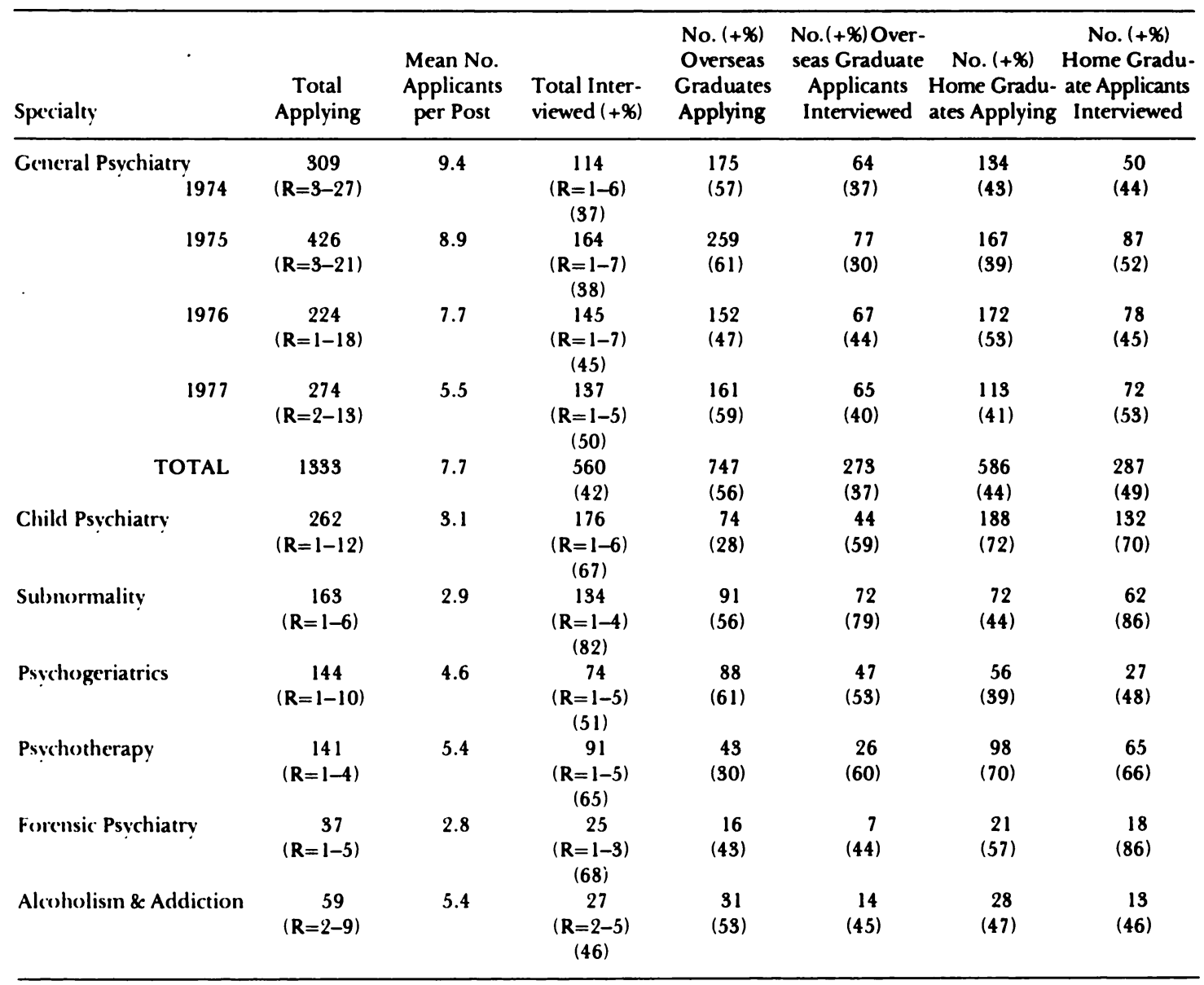

the candidates' apparent inability to put their training to good account, often finding it difficult to relate their theoretical knowledge to practical issues. The calibre of those interviewed seemed particularly low in subnormality, but the findings for general psychiatry and psychogeriatrics give little cause for complacency; there is a much healthier picture in respect of psychotherapy and child psychiatry.

The falling numbers of applicants for general psychiatry would seem to confirm the inadequate number of senior registrars in post, but another finding with implications for recruitment and manpower is the number of posts where no recommendation for appointment was made. The problem for psychogeriatrics is somewhat different. Apart from the large number of applicants who seem to lack experience in geriatrics, the number of posts which were recorded by the College assessors as having too large a commitment is alarmingly high, and there are indications that unsuitable posts are still being advertised.

The quality of applicants, admittedly made on an impressionistic basis by the College representative, is disturbingly low in general psychiatry and psychogeriatrics, but alarmingly so for subnormality. Because of small numbers it is less easy to comment on forensic psychiatry and the dependencies, but psychotherapy particularly seems to be attracting a large proportion of better-than-average candidates, though even in this field there is a discrepancy in quality between London and elsewhere.

In the first three years the proportion of overseas graduates appointed to posts in general psychiatry 
reflects very closely their representation in the senior registrar grade, but there was a sharp fall in 1977. The numbers applying for posts have exceeded the number of home graduates (except in 1976), although overseas graduates stand rather less chance of being interviewed. Nevertheless, over the four years the proportion of interviewees who were overseas graduates-491-was higher than would be expected from the number of overseas graduates holding senior registrar posts. There are no ready explanations for this finding although light may be thrown on this when the senior registrar follow-up study is completed $^{1,2}$, but one possibility is that there are a comparatively small number of overseas senior registrars who repeatedly apply for posts and who then meet with no early success. Another discrepancy is between the proportion of senior registrars in mental deficiency and the proportion of overseas graduates appointed to posts, but here the small number of appointees may be producing an artefact.

Peter Brook, Sub-Dean

References

1 The Senior Registrar Survey: First Year Follow-Up News and Notes, May 1976. 14-15.

2 The Senior Registrar Survey: Second Year Follow-Up: British Joumal of Psychiatry. 132, 96-98.

\title{
REFLECTIONS ON MENTAL HEALTH REVIEW TRIBUNALS *
}

\author{
By James A. Cooke \\ Barrister-at-law, Chairman of SE and SW Thames Regions Mental Health Review Tribunal
}

Towards the latter part of 1959 some thirty lawyers met at the Ministry of Health under the chairmanship of the late Sir Sidney Littlewood. We were the first members of the legal panels of the Mental Health Review Tribunals for the four London regions.

All of us had a considerable experience of advocacy and Court procedures-mainly in Criminal Courts; none of us had any knowledge of the treatment of mental disorders or of mental hospitals.

At the time, the Ministry had little idea of the volume of applications to be dealt with in the early days. The only guidance we received was within the covers of the Act itself and the Mental Health Tribunal Rules. We were left to devise our own procedures and to set our own standards.

Tribunals should not be regarded by psychiatrists as a challenge to their competence or Tribunal's decisions a criticism of their judgement. It should be remembered that the Tribunal's decision is based on the patient's condition after a period of treatment, that is at the time of the determination, and the situation may have changed since the order was made or last renewed.

There is not, in essence, any conflict of interest between the RMO or the detaining authority on the one hand and the Tribunal on the other. Both are seeking to hold a delicate balance between the qualified right of the individual to his liberty on the one hand and his welfare and the needs of the community on the other.
One should sympathize with the psychiatrist who has to exercise his powers alone. He should not resent the opportunity of sharing a heavy burden with the Tribunal. Indeed it is the practice in at least one Special Hospital to invite patients seeking discharge to ask for a reference to a Tribunal.

Above all a patient should never be discouraged from making an application or influenced to withdraw. Every withdrawal is investigated by the Tribunal to make sure it is not made under duress. An application, once made, exhausts the patient's rights until the next renewal. An application withdrawn is a valuable right thrown away. Hence the change suggested in the recent Discussion Paper.

Each Regional Tribunal has developed over the years in isolation from all others save in those few cases where there has been a common Chairman of more than one Tribunal. There has been little opportunity for developing a cohesive system throughout England and Wales, or for achieving common standards.

After the initial formalities the only procedures which each Tribunal must necessarily follow are the ones laid down in the Act and the Rules.

The Rules purport to divide determinations into two classes namely informal determinations and formal hearings. In fact there is very little difference. It

-Abbreviated from a paper read at a meeting of the Southern Division of the College, 20 September 1978. 